\title{
Effect of the Tillage System on the Properties of Humic Acids of Soil of the Kujawy Region in Poland
}

\author{
Magdalena Banach-Szott ${ }^{1}$, Iwona Jaskulska ${ }^{2}$, Bozena Debska ${ }^{1} \&$ Dariusz Jaskulski ${ }^{2}$ \\ ${ }^{1}$ Department of Environmental Chemistry, University of Science and Technology, Bydgoszcz, Poland \\ ${ }^{2}$ Department of Agronomy, University of Science and Technology, Bydgoszcz, Poland \\ Correspondence: Magdalena Banach-Szott, Department of Environmental Chemistry, University of Science and \\ Technology, 6 Bernardynska St., 85-029 Bydgoszcz, Poland. Tel: 48-523-749-538. E-mail: mbanach@utp.edu.pl
}

\author{
Received: April 23, $2020 \quad$ Accepted: June 8, $2020 \quad$ Online Published: July 15, 2020 \\ doi:10.5539/jas.v12n8p14 URL: https://doi.org/10.5539/jas.v12n8p14
}

The research is financed by the Ministry of Science and Higher Education.

\begin{abstract}
The aim of this study has been to determine the properties of humic acids of soil depending on the tillage system applied. The study covered the soil where plough tillage, strip-till and ploughless tillage were used, and so the systems which differed completely in the way they affect the post-harvest residue, "plant residue management". From averaged samples of soil humic acids (HAs) were extracted to identify their elemental composition, spectrometric properties for the UV-VIS and IR range as well as hydrophilic-hydrophobic properties.

With the results one can conclude that the humic acids of the soil under plough tillage show a lower degree of humification as compared with HAs of ploughless tillage, whereas the parameters recorded for HAs of the soil with strip-till point to the similarity to HAs of soil with plough tillage and ploughless tillage. With that in mind, with some approximation, the degree of humification (maturity) of HAs can be ordered as follows: HAs with plough tillage $<$ HAs with strip-till $<$ HAs with ploughless tillage. Thus one can conclude that the tillage method combines two primary objectives; ensuring conditions favourable to plant growth and development and the effort to maintain the possibly highest humus stability.
\end{abstract}

Keywords: plough tillage, ploughless tillage, strip-till, Cambisols

\section{Introduction}

Over the recent years the concept of sustainable development has been popularised by the so-called conservation tillage (Friedrich, Derpsch, \& Kassam, 2012). As reported by e.g., A. K. M. S. Islam, Saleque, Hossain, and A. K. M. A. Islam (2015), Strickland et al. (2015), and Si et al. (2018), abandoning plough tillage and introducing simplified tillage, including strip-till, results in the accumulation of organic carbon and nutrients in topsoil. In strip-till deeply-loosened strips account for one third of the field, and $60-75 \%$ of plant residue remains on its surface (Morris, Miller, Orson, \& Froud-Williams, 2010). Fernandez, Sorensenb, and Villamil (2015) have demonstrated that strip-till, as compared with ploughless system, ensures a better environment for root growth and development, which is of key importance for water and nutrients uptake. As seen from the research conducted by Al-Kaisi, Douelle, and Kwaw-Mensah (2014) and by Fernandez et al. (2015), after a few years of applying strip-till, the content of organic matter in soil increases. Powlson et al. (2012) stress that simplified tillage is important not only to increase the content of organic matter in soils but also to limit the emissions of greenhouse gases. Indeed Busari, Kukal, Kaur, Bhatt, and Dulazi (2015) claim that it is necessary to apply simplified tillage as part of the soil and atmosphere protection strategy, and thus to alleviate the climate changes and to preserve the biodiversity.

Soil protection mostly involves the protection of the resources of organic matter. The key organic matter component are humus substances, including humic acids, being the most common organic compounds found in nature. Humic acids (HAs) take part in all the processes which occur in soil and affect its biological (biodiversity, growth stimulation and plant development), physical and chemical properties. Humic acids affect the soil structure and thus the level of soil aeration, soil permeability and water holding capacity. The HAs make the soils dark in colour, which facilitates soil warming. The chemical composition and the energy value of HAs make 
them a serious source of carbon and nitrogen as well as facilitate soil buffer properties development. There has been also demonstrated a dependence between the content of humus and the plant health status. Therefore, the amount and quality of humic acids are a major indicator of soil fertility and productivity and they depend on the habitat (climate, soil) and anthropogenic factors (tillage and plant growing, fertilisation, crop rotation) (Gonet, 1989; Dou, Zhang, \& Li, 2008; Debska, Drag, \& Tobiasova, 2012; Kwiatkowska-Malina, 2015; Zhang et al., 2017). Interestingly, humic acids are the main link in carbon sequestration and releasing $\mathrm{CO}_{2}$ to the atmosphere as well as in environment detoxication (Tan, 2012; Gomes de Melo, Motta, \& Santana, 2016).

The basic indicators used to evaluate the properties of humic acids are the elemental composition, including the values of atomic ratios: $\mathrm{H} / \mathrm{C}, \mathrm{O} / \mathrm{C}, \mathrm{N} / \mathrm{C}$ determined from that composition as well as the degree of internal oxidation, coefficients of absorbance $\mathrm{A}_{2 / 4}, \mathrm{~A}_{2 / 6}, \mathrm{~A}_{4 / 6}$ and $\Delta \operatorname{logK}$, IR spectra and hydrophilic-hydrophobic parameters (Debska, Banach-Szott, Dziamski, \& Gonet, 2010; Debska et al., 2012; Ferreira, 2013; Enev, Pospisilova, Klucakova, Liptaj, \& Doskocil, 2014; Trubetskaya, Trubetskoj, \& Richard, 2014; Tinoco, 2015; Rodriguez, 2016; Hayes \& Swift, 2018). As seen from the literature review special role has been documented for the applying natural fertiliser (FYM, liguid manure) organic (compost, green manure) and mineral fertilisers or post-harvest residue for the properties of humic acids. Researching humic acids has demonstrated (Gonet, 1989; Kwiatkowska-Malina, 2015; Zhang et al., 2017), e.g., that FYM fertilisation results in their aliphatization, increased susceptibility to oxidation, decreased average molecular weight and in changes in optical properties, as compared with the properties of the humic acids of non-fertilised soils. The humic acids of the soils treated only with mineral fertilisers, as compared with the HAs of the soil fertilised with FYM, show a greater share of aromatic structures, a lower susceptibility to oxidation as well as higher values of absorbance at the wavelength of $465 \mathrm{~nm}$. As reported by Debska (2004), fertilising soils with slurry results in the formation of humic acids with a greater share of hydrophobic fractions, a lower value of the degree of internal oxidation, a higher share of aromatic structures as compared with the HAs fertilised only with NPK.

The directions of post-harvest residue transformation are mostly determined by its chemical composition, mostly the value of the ratio of carbon to nitrogen as well as the content of easily decomposable compounds (Carvalho, Bustamante, Alcantara, Resck, \& Lemos, 2009; Debska et al., 2012).

Considering the role of humic acids in the soil environment, an attempt has been made to determine the effect of various tillage systems (plough tillage, strip-till and ploughless tillage) on their properties especially a comparison of the so-called conservation crops with plough tillage.

The tillage systems compared: plough, ploughless and strip-till, differ essentially in the way they affect the post-harvest residue "the management of plant residue", the basic source of organic carbon in arable soils. Plough tillage, by reversing the soil, covers the residue a dozen or so centimetres deep. Ploughless tillage mixes the organic matter evenly with the soil layer down to $20-30 \mathrm{~cm}$ deep. Both systems strongly loosen and aerate the soil. After strip-till most plant residue remains on the surface of the non-tilled soil. Only narrow soil strips are loosened and aerated. The present research has assumed a hypothesis that such a strong diversification of the conditions of organic matter transformations in soil can, already after 4 years, significantly, change the properties of humic acids.

The aim of this study has been to determine the properties of humic acids of soil depending on the tillage system applied. The humic acids were assayed to identify their elemental composition, spectrometric properties for the UV-VIS and IR range as well as hydrophilic-hydrophobic properties and so the parameters which significantly determine the role of humic acids in the soil environment.

\section{Materials and methods}

\subsection{Materials}

The soil was sampled from a single-factor field experiment located at Smielin $\left(53^{\circ} 09^{\prime} 04^{\prime \prime} \mathrm{N} ; 17^{\circ} 29^{\prime} 11^{\prime \prime} \mathrm{E}\right)$, the kujawsko-pomorskie province, Poland. The experiment factor was made up by the tillage system for winter rapeseed-winter wheat crop rotation:

- $\quad$ plough tillage $(O)$ (average-deep pre-sow plough, pre-sowing mineral fertilisation, seedbed preparation, seed-drill sowing);

- $\quad$ strip-till $(S)$ (strip tillage, pre-sowing mineral fertilisation and strip sowing with a single trip of the tillage unit);

- ploughless tillage $(H)$ (entire-space, ploughless, loosening, average-deep tillage; pre-sowing mineral fertilisation; seed drilling with the combined aggregate and seed drill). 
The experiment was set up in four replications in Haplic Cambisols (WRB, 2014), in 0-20 cm layer, with the content of sand, silt and clay fractions of $41.4 \%, 52.3 \%, 6.3 \%$, respectively.

The soil (from each plot) was sampled from three layers 0-15 cm (1), 15-30 cm (2) and 30-50 cm (3), in the fourth research year after harvesting winter wheat. For each tillage system the soil was sampled from four plots; the replications. From each plot 12 samples were taken along both diagonals. All the samples from the plot were combined and carefully mixed. Having dried in room temperature, the samples were sieved. For sample assaying the symbols given in brackets were used, e.g., $\mathrm{O} 1$ stands for the soil sampled under plough tillage from the $0-15 \mathrm{~cm}$ layer.

\subsection{Methods}

From soil samples there were extracted humic acids (HAs) following the standard procedure described by Debska et al. (2010).

The humic acids separated were analysed for:

- $\quad$ C, H, N and ash content with Series II 2400 CHN analyser, Perkin Elmer (Debska et al., 2012);

- $\quad$ the optical properties in the UV-VIS range with Lambda 20 spectrophotometer, Perkin-Elmer (Debska, Maciejewska, \& Kwiatkowska, 2002);

- $\quad$ the optical properties in the IR range with FT-IR Spectrometer, Spectrum BX, Perkin-Elmer (Coccoza \& Miano, 2002);

- $\quad$ hydrophilic and hydrophobic properties with a liquid chromatograph (HPLC series 200, Perkin-Elmer) (Debska et al., 2010).

In the humic acids preparations ash content was lower than $2 \%$.

\subsection{Statistical Analyses}

The significance of differences of the parameters, depending on the tillage method and depth, was evaluated with Duncan's Tukey test. The effect of the tillage method on the properties of the soils was defined with cluster analysis. Data clustering was performed with the Ward method. Cluster analysis facilitates the determination of the similarities of the treatments (Euclidean distance evaluation) using their characteristics. The treatments with similar properties are located on dendrograms in homogenous groups (K. A. Gomez \& A. A. Gomez, 1983). The above relationships were determined using statistical software STATISTICA MS 12.

\section{Results and Discussion}

\subsection{Elemental Composition}

The elemental composition is considered one of the basic features of humus substances commonly used to identify them and to draw conclusions about their structure. The key elements being part of humic acids are carbon, hydrogen, oxygen and nitrogen (Gonet \& Debska, 1998; Debska et al., 2012; Tan, 2012; Gomes de Melo et al., 2016; Zhang et al., 2017). The results of the analysis of the elemental composition (in atomic percentage) of humic acids (HAs) isolated from respective layers are presented in Table 1. The highest average content of carbon (C) was found for HAs of the soil under ploughless tillage. There were demonstrated no significant differences between the content of carbon in HAs molecules under plough tillage and strip-till. The humic acids of the soil under plough tillage showed a significantly higher content of hydrogen as compared with HAs of the soil under ploughless tillage. The tillage method did not have a significant effect on the share of nitrogen and oxygen in the molecules of humic acids. Interestingly, the highest contents of carbon and the lowest contents of hydrogen were recorded for HAs isolated from the soil sampled from the $15-50 \mathrm{~cm}$ layers. It was also observed that HAs of the soil of the 30-50 cm layer under plough tillage and strip-till showed a slightly higher content of oxygen as compared with the content of that element in 0-30 cm layers. 
Table 1. Elemental composition of humic acids

\begin{tabular}{|c|c|c|c|c|c|c|c|c|c|}
\hline \multirow{2}{*}{ Sample } & \multicolumn{4}{|c|}{ [\% Atomic] } & \multirow{2}{*}{$-\mathrm{H} / \mathrm{C}$} & \multirow{2}{*}{$\mathrm{N} / \mathrm{C}$} & \multirow{2}{*}{$\mathrm{O} / \mathrm{C}$} & \multirow{2}{*}{$\mathrm{O} / \mathrm{H}$} & \multirow{2}{*}{$\omega$} \\
\hline & $\mathrm{C}$ & $\mathrm{H}$ & $\mathrm{N}$ & $\mathrm{O}$ & & & & & \\
\hline \multicolumn{10}{|c|}{ Plough tillage } \\
\hline O1* & 34.59 & 42.02 & 2.78 & 20.61 & 1.22 & 0.080 & 0.59 & 0.490 & 0.218 \\
\hline $\mathrm{O} 2$ & 35.57 & 41.06 & 2.80 & 20.57 & 1.15 & 0.079 & 0.578 & 0.501 & 0.239 \\
\hline $\mathrm{O} 3$ & 36.06 & 39.93 & 2.74 & 21.27 & 1.11 & 0.076 & 0.590 & 0.533 & 0.301 \\
\hline$O$ (mean) & $35.41 \pm 0.43 \mathrm{~b}^{* *}$ & $41.00 \pm 0.60 \mathrm{a}$ & $2.77 \pm 0.02 \mathrm{a}$ & $20.82 \pm 0.23 \mathrm{a}$ & $1.16 \pm 0.03 \mathrm{a}$ & $0.078 \pm 0.001 \mathrm{a}$ & $0.586 \pm 0.04 \mathrm{a}$ & $0.508 \pm 0.012 b$ & $0.253 \pm 0.025 \mathrm{c}$ \\
\hline \multicolumn{10}{|l|}{ Strip-till } \\
\hline S1 & 35.57 & 40.87 & 2.76 & 20.81 & 1.15 & 0.078 & 0.585 & 0.509 & 0.254 \\
\hline S2 & 35.63 & 40.90 & 2.81 & 20.65 & 1.15 & 0.079 & 0.580 & 0.505 & 0.248 \\
\hline $\mathrm{S} 3$ & 36.40 & 38.98 & 2.70 & 21.92 & 1.07 & 0.074 & 0.602 & 0.563 & 0.357 \\
\hline $\mathrm{S}$ (mean) & $35.87 \pm 0.27 \mathrm{~b}$ & $40.25 \pm 0.64 \mathrm{ab}$ & $2.76 \pm 0.03 a$ & $21.13 \pm 0.40 \mathrm{a}$ & $1.12 \pm 0.03 \mathrm{a}$ & $0.077 \pm 0.002 \mathrm{a}$ & $0.589 \pm 0.007 \mathrm{a}$ & $0.526 \pm 0.019 \mathrm{ab}$ & $0.286 \pm 0.035 b$ \\
\hline \multicolumn{10}{|c|}{ Ploughless tillage } \\
\hline H1 & 36.72 & 39.84 & 2.91 & 20.49 & 1.08 & 0.079 & 0.558 & 0.514 & 0.269 \\
\hline $\mathrm{H} 2$ & 37.08 & 38.38 & 2.80 & 21.75 & 1.04 & 0.075 & 0.587 & 0.567 & 0.364 \\
\hline $\mathrm{H} 3$ & 37.62 & 38.58 & 2.83 & 20.97 & 1.03 & 0.075 & 0.558 & 0.544 & 0.315 \\
\hline $\mathrm{H}$ (mean) & $37.14 \pm 0.26 \mathrm{a}$ & $38.93 \pm 0.46 \mathrm{~b}$ & $2.85 \pm 0.03 \mathrm{a}$ & $21.01 \pm 0.37 \mathrm{a}$ & $1.05 \pm 0.02 \mathrm{~b}$ & $0.076 \pm 0.001 \mathrm{a}$ & $0.568 \pm 0.010 \mathrm{a}$ & $0.542 \pm 0.015 \mathrm{a}$ & $0.316 \pm 0.027 \mathrm{a}$ \\
\hline \multicolumn{10}{|c|}{ Mean values for layers (depth of layers in $\mathrm{cm}$ ) } \\
\hline $0-15$ & $35.62 \pm 0.62 b$ & $40.91 \pm 0.63 \mathrm{a}$ & $2.82 \pm 0.05 \mathrm{a}$ & $20.64 \pm 0.09 \mathrm{a}$ & $1.15 \pm 0.04 \mathrm{a}$ & $0.079 \pm 0.001 \mathrm{a}$ & $0.578 \pm 0.010 \mathrm{a}$ & $0.504 \pm 0.007 \mathrm{~b}$ & $0.247 \pm 0.015 \mathrm{c}$ \\
\hline $15-30$ & $36.09 \pm 0.49 \mathrm{ab}$ & $40.11 \pm 0.87 \mathrm{~b}$ & $2.80 \pm 0.01 \mathrm{a}$ & $20.99 \pm 0.38 \mathrm{a}$ & $1.11 \pm 0.04 \mathrm{ab}$ & $0.078 \pm 0.001 \mathrm{a}$ & $0.582 \pm 0.003 \mathrm{a}$ & $0.524 \pm 0.021 \mathrm{ab}$ & $0.284 \pm 0.040 \mathrm{~b}$ \\
\hline $30-50$ & $36.69 \pm 0.47 \mathrm{a}$ & $39.16 \pm 0.40 \mathrm{~b}$ & $2.76 \pm 0.04 \mathrm{a}$ & $21.39 \pm 0.28 \mathrm{a}$ & $1.070 .02 \mathrm{~b}$ & $0.075 \pm 0.001 \mathrm{a}$ & $0.583 \pm 0.013 \mathrm{a}$ & $0.547 \pm 0.009 \mathrm{a}$ & $0.324 \pm 0.017 \mathrm{a}$ \\
\hline
\end{tabular}

The share of the elements in the molecules of humic acids facilitated the calculation of the values of atomic ratios. The numerical values of atomic ratios allow for an approximate determination of the structure of the molecules of humic acids by evaluating the degree of condensation of aromatic rings $(\mathrm{H} / \mathrm{C}$ ratio $)$ and the degree of their maturity (O/C, O/H, w) (Dou et al., 2008; Debska et al., 2012; Ferreira et al., 2013; Tinoco et al., 2015; Tan, 2012). As seen from Table 1, the cultivation method has modified the values of ratio $\mathrm{H} / \mathrm{C}, \mathrm{O} / \mathrm{H}$ and the degree of internal oxidation. The humic acids of the soil under ploughless tillage showed the lowest value of ratio $\mathrm{H} / \mathrm{C}$ and the highest value of the degree of internal oxidation. The HAs of the soil under plough tillage have recorded the lowest value of the degree of internal oxidation. The values of ratios $\mathrm{H} / \mathrm{C}$ and $\mathrm{O} / \mathrm{H}$ of the humic acids of the soil under plough tillage and strip-till did not differ significantly. The parameters were also determined by the depth the soil was sampled for research from. The HAs of the deepest layer $(30-50 \mathrm{~cm})$ showed the highest value of the degree of internal oxidation and a significantly higher value of ratio $\mathrm{O} / \mathrm{H}$ and a lower value of ratio $\mathrm{H} / \mathrm{C}$ than $\mathrm{HAs}$ from $0-15$ $\mathrm{cm}$ layer. It should be stressed that the greatest changes in the value of the degree of internal oxidation for ploughless tillage were observed between the humic acids sampled from 0-15 and 15-30 cm layers, whereas for plough tillage and strip-till the greatest difference was noted between the humic acids of 0-30 and 30-50 cm layers. The results definitely indicate that HAs under ploughless tillage show a higher degree of condensation of aromatic nucleus (lower $\mathrm{H} / \mathrm{C}$ values) and, as a result, a higher degree of maturity $(\omega, \mathrm{O} / \mathrm{H})$ as compared with HAs under plough tillage and less considerably-strip-till.

\subsection{Spectrometric Parameters of Humic Acids in the UV-VIS Range}

The method of electron absorption has been long applied in the research of humus substances. In the UV-VIS spectra of typical humic acids, in general, there are no maximums and the spectrum assumes the shape of a monotonically decreasing line. Interpreting the spectra of humic acids, the values of absorbance at wavelengths $280,400,465,600$ and $665 \mathrm{~nm}$ are considered mostly to calculate the ratios $\mathrm{A}_{2 / 4}, \mathrm{~A}_{2 / 6}, \mathrm{~A}_{4 / 6}$ and coefficient $\Delta \operatorname{logK}$. $\mathrm{A}_{2 / 4}, \mathrm{~A}_{2 / 6}, \mathrm{~A}_{4 / 6}$ and $\Delta \log \mathrm{K}$ are parameters which can be used to evaluate the level of advancement of the process of humification of organic materials and the characteristics of the humus substances produced. In general humic acids with a lower molecular weight and a lower degree of humification show higher values of coefficients $\mathrm{A}_{2 / 4}, \mathrm{~A}_{2 / 6}$, $\mathrm{A}_{4 / 6}$ and $\Delta \log \mathrm{K}$ as compared with HAs with a higher degree of "maturity" (Kumada, 1987; Debska, 2004; Enev et al., 2014; Tinoco et al., 2015; Rodriguez, Schlenger, \& García-Valverde, 2016). 
Table 2. Absorbance values and coefficients of absorbance of humic acids

\begin{tabular}{|c|c|c|c|c|c|c|c|}
\hline \multirow{2}{*}{ Sample } & \multicolumn{3}{|c|}{ Wavelength [nm] } & \multirow{2}{*}{$-\mathrm{A}_{2 / 4}$} & \multirow{2}{*}{$\mathrm{A}_{2 / 6}$} & \multirow{2}{*}{$\mathrm{A}_{4 / 6}$} & \multirow{2}{*}{$\Delta \log \mathrm{K}$} \\
\hline & 280 & 400 & 665 & & & & \\
\hline \multicolumn{8}{|c|}{ Plough tillage } \\
\hline $\mathrm{O} 1 *$ & 5.06 & 1.30 & 0.117 & 7.41 & 43.25 & 5.84 & 0.766 \\
\hline $\mathrm{O} 2$ & 5.22 & 1.41 & 0.137 & 6.86 & 38.10 & 5.55 & 0.744 \\
\hline $\mathrm{O} 3$ & 5.79 & 1.57 & 0.169 & 6.56 & 34.26 & 5.22 & 0.703 \\
\hline $\mathrm{O}($ mean $)$ & $5.36 \pm 0.22 \mathrm{~b} * *$ & $1.42 \pm 0.08 \mathrm{~b}$ & $0.141 \pm 0.015 b$ & $6.94 \pm 0.25 \mathrm{a}$ & $38.54 \pm 2.60 \mathrm{a}$ & $5.54 \pm 0.18 \mathrm{a}$ & $0.738 \pm 0.018 \mathrm{a}$ \\
\hline \multicolumn{8}{|l|}{ Strip-till } \\
\hline $\mathrm{S} 1$ & 5.33 & 1.40 & 0.136 & 7.15 & 39.19 & 5.48 & 0.751 \\
\hline $\mathrm{S} 2$ & 5.64 & 1.56 & 0.164 & 6.38 & 34.39 & 5.39 & 0.715 \\
\hline $\mathrm{S} 3$ & 6.35 & 1.74 & 0.202 & 6.32 & 31.44 & 4.97 & 0.680 \\
\hline $\mathrm{S}($ mean) & $5.77 \pm 0.30 \mathrm{a}$ & $1.56 \pm 0.10 \mathrm{a}$ & $0.167 \pm 0.019 a$ & $6.617 \pm 0.27 \mathrm{a}$ & $35.01 \pm 2.26 \mathrm{~b}$ & $5.28 \pm 0.16 \mathrm{~b}$ & $0.715 \pm 0.020 \mathrm{~b}$ \\
\hline \multicolumn{8}{|c|}{ Ploughless tillage } \\
\hline $\mathrm{H} 1$ & 5.53 & 1.44 & 0.138 & 7.18 & 40.07 & 5.58 & 0.750 \\
\hline $\mathrm{H} 2$ & 5.35 & 1.49 & 0.153 & 6.44 & 34.97 & 5.43 & 0.721 \\
\hline H3 & 5.89 & 1.56 & 0.164 & 6.72 & 35.91 & 5.35 & 0.707 \\
\hline $\mathrm{H}($ mean) & $5.59 \pm 0.16 \mathrm{ab}$ & $1.50 \pm 0.04 \mathrm{ab}$ & $0.152 \pm 0.008 \mathrm{ab}$ & $6.78 \pm 0.22 \mathrm{a}$ & $36.98 \pm 1.57 \mathrm{ab}$ & $5.45 \pm 0.07 \mathrm{ab}$ & $0.726 \pm 0.013 \mathrm{ab}$ \\
\hline \multicolumn{8}{|c|}{ Mean values for layers (depth of layers in $\mathrm{cm}$ ) } \\
\hline $0-15$ & $5.31 \pm 0.13 b$ & $1.38 \pm 0.04 b$ & $0.130 \pm 0.007 \mathrm{c}$ & $7.25 \pm 0.08 \mathrm{a}$ & $40.84 \pm 1.23 \mathrm{a}$ & $5.63 \pm 0.11 \mathrm{a}$ & $0.756 \pm 0.005 \mathrm{a}$ \\
\hline $15-30$ & $5.40 \pm 0.12 b$ & $1.49 \pm 0.04 b$ & $0.151 \pm 0.008 \mathrm{~b}$ & $6.56 \pm 0.15 b$ & $35.82 \pm 1.15 b$ & $5.46 \pm 0.05 \mathrm{ab}$ & $0.727 \pm 0.009 b$ \\
\hline $30-50$ & $6.01 \pm 0.17 \mathrm{a}$ & $1.62 \pm 0.06 \mathrm{a}$ & $0.178 \pm 0.012 \mathrm{a}$ & $6.53 \pm 0.12 b$ & $33.87 \pm 1.30 \mathrm{~b}$ & $5.18 \pm 0.11 \mathrm{~b}$ & $0.697 \pm 0.008 \mathrm{c}$ \\
\hline
\end{tabular}

Note. *: layers 0-15 cm (1), 15-30 cm (2), 30-50 cm (3); **: Mean values followed by common letter are not significantly different at the $5 \%$ level.

As seen from Table 2, the humic acids of variants "S" and " $\mathrm{H}$ ", in general, revealed similar values of absorbance and absorbance ratios. The lowest values of absorbance and the highest values of the coefficients of absorbance were recorded for HAs of the soil under plough tillage, however, a significant difference was recorded between HAs of variants "O" and 'S". Interestingly, HAs from the $0-15 \mathrm{~cm}$ layer showed, in general, higher values of the coefficients of absorbance, as compared with HAs from $15-50 \mathrm{~cm}$ layers. As recorded by Kumada (1987), humic acids, based on the pattern of UV-VIS spectra, can be divided into three basic types: type A-with humic acids with a high degree of humification, for which $\Delta \operatorname{logK}$ assumes the values up to 0.6 , type B-with values $\Delta \operatorname{logK}$ from 0.6 to 0.8 and type $R_{p}$ - with acids with the values of the coefficient from 0.8 to 1.1 . The values of coefficient $\Delta \log \mathrm{K}$ of the humic acids ranged from 0.680 to 0.766 , so they can be considered one type- $\mathrm{B}$.

\subsection{Hydrophilic-Hydrophobic Properties of Humic Acids}

Sample chromatograms of humic acids are presented in Figure 1. The humic acids, irrespective of the tillage method, showed, in general, the presence of peaks in the range 3-25 min, from which the peaks in the range from 3 to $7 \mathrm{~min}$ correspond to the fractions of humic acids with greater hydrophilic properties and the peaks in the range 12-25 min - hydrophobic properties. In the range corresponding to the hydrophobic fractions 3 sub-ranges were identified, divided into: HOB-1-12-16 min, HOB-2-16-20 min and HOB-3-20-25 min. Most hydrophobic are the fractions with the longest retention time (Debska et al., 2012; Trubetskaya et al., 2014), the share of which in the humic acids analysed was lowest. The share of hydrophilic fractions in the molecules of humic acids ranged from about 20 to $21 \%$ (HAs of variants " $\mathrm{S}$ " and " $\mathrm{H}$ " of $30-50 \mathrm{~cm}$ layer) to $23.84 \%-\mathrm{HAs}$ of the soil under plough tillage (0-15 cm layer) (Table 3). The total share of hydrophobic fractions did not depend on the tillage method significantly and it ranged from 76.16 (HAs of variant "O", $0-15 \mathrm{~cm}$ layer) to $79.72 \%-\mathrm{HAs}$ of the soil under strip-till (30-50 cm layer). 


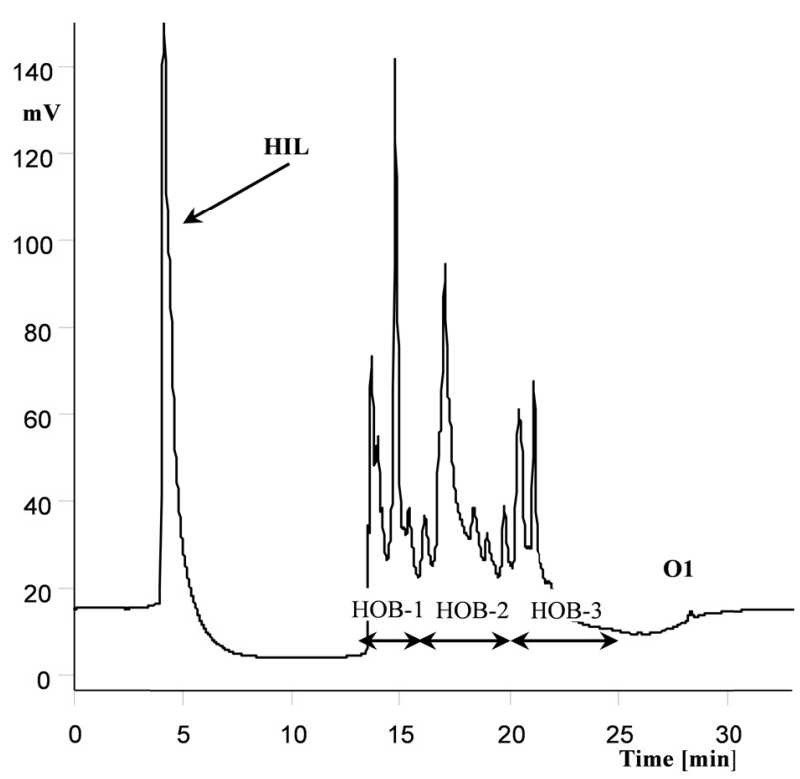

Figure 1. Selected RP-HPLC chromatogram of humic acids

The share of hydrophilic and hydrophobic fractions results in their ratio (HIL/ $/ \mathrm{HOB})$. The highest value of $\mathrm{HIL} / \Sigma \mathrm{HOB}$ was showed for HAs under plough tillage. The values of ratio HIL $/ \Sigma \mathrm{HOB}$ for HAs of $30-50 \mathrm{~cm}$ layer were lower as compared with HAs of the soil from $0-15 \mathrm{~cm}$ layer. Trubetskaya et al. (2014) have reported that HAs with a higher share of hydrophobic fractions reveal a higher molecular weight, which coincides with earlier information presented by Kumada (1985) that the share of hydrophobic fractions increases with an increase in the degree of humification, namely lower values of ratio $\mathrm{HIL} / \mathrm{LHOB}$ are recorded for $\mathrm{HAs}$ with a higher degree of maturity.

Table 3. Hydrophilic-hydrophobic properties of humic acids

\begin{tabular}{|c|c|c|c|c|c|c|}
\hline \multirow{2}{*}{ Sample } & HIL & HOB-1 & HOB-2 & HOB-3 & $\sum \mathrm{HOB}$ & \multirow{2}{*}{$\mathrm{HIL} / \sum \mathrm{HOB}$} \\
\hline & \multicolumn{5}{|c|}{ [\%] } & \\
\hline \multicolumn{7}{|c|}{ Plough tillage } \\
\hline $\mathrm{O} 1 *$ & 23.84 & 30.32 & 27.40 & 18.44 & 76.16 & 0.313 \\
\hline $\mathrm{O} 2$ & 22.43 & 30.64 & 28.33 & 18.60 & 77.57 & 0.289 \\
\hline $\mathrm{O} 3$ & 22.23 & 32.11 & 28.62 & 17.04 & 77.77 & 0.286 \\
\hline $\mathrm{O}$ (mean) & $22.83 \pm 0.51 \mathrm{a}^{* *}$ & $31.02 \pm 0.55 \mathrm{a}$ & $28.12 \pm 0.37 \mathrm{a}$ & $18.03 \pm 0.50 \mathrm{a}$ & $77.17 \pm 0.51 \mathrm{~b}$ & $0.296 \pm 0.009 \mathrm{a}$ \\
\hline \multicolumn{7}{|l|}{ Strip-till } \\
\hline S1 & 22.95 & 33.98 & 27.47 & 15.60 & 77.05 & 0.298 \\
\hline S2 & 21.00 & 30.52 & 28.16 & 19.42 & 78.10 & 0.280 \\
\hline S3 & 20.28 & 30.97 & 28.60 & 20.15 & 79.72 & 0.254 \\
\hline $\mathrm{S}$ (mean) & $21.71 \pm 0.80 \mathrm{ab}$ & $31.82 \pm 1.09 \mathrm{a}$ & $28.08 \pm 0.33 \mathrm{a}$ & $18.39 \pm 1.41 \mathrm{a}$ & $78.29 \pm 0.78 \mathrm{ab}$ & $0.277 \pm 0.013 b$ \\
\hline \multicolumn{7}{|c|}{ Ploughless tillage } \\
\hline H1 & 22.35 & 31.16 & 28.32 & 18.17 & 77.65 & 0.288 \\
\hline $\mathrm{H} 2$ & 21.86 & 31.34 & 28.31 & 18.49 & 78.14 & 0.280 \\
\hline H3 & 20.58 & 32.19 & 28.58 & 18.65 & 79.42 & 0.259 \\
\hline $\mathrm{H}$ (mean) & $21.60 \pm 0.53 b$ & $31.56 \pm 0.32 \mathrm{a}$ & $28.40 \pm 0.09 \mathrm{a}$ & $18.44 \pm 0.14 \mathrm{a}$ & $78.40 \pm 0.53 \mathrm{a}$ & $0.276 \pm 0.009 \mathrm{~b}$ \\
\hline \multicolumn{7}{|c|}{ Mean values for layers (depth of layers in $\mathrm{cm}$ ) } \\
\hline $0-15$ & $23.05 \pm 0.43 \mathrm{a}$ & $31.82 \pm 1.11 \mathrm{a}$ & $27.73 \pm 0.30 \mathrm{a}$ & $17.40 \pm 0.91 \mathrm{a}$ & $76.95 \pm 0.43 b$ & $0.300 \pm 0.007 \mathrm{a}$ \\
\hline $15-30$ & $22.06 \pm 0.42 \mathrm{ab}$ & $30.83 \pm 0.26 \mathrm{a}$ & $28.27 \pm 0.05 \mathrm{a}$ & $18.84 \pm 0.29 \mathrm{a}$ & $77.94 \pm 0.18 \mathrm{ab}$ & $0.283 \pm 0.003 \mathrm{ab}$ \\
\hline $30-50$ & $21.03 \pm 0.61 b$ & $31.58 \pm 0.39 \mathrm{a}$ & $28.60 \pm 0.01 \mathrm{a}$ & $18.61 \pm 0.90 \mathrm{a}$ & $78.97 \pm 0.61 \mathrm{a}$ & $0.266 \pm 0.010 \mathrm{~b}$ \\
\hline
\end{tabular}

Note. *: layers 0-15 cm (1), 15-30 cm (2), 30-50 cm (3); **: Mean values followed by common letter are not significantly different at the $5 \%$ level. 


\subsection{FTIR-Spectra}

The spectra of the humic acids analysed, irrespective of the tillage method applied, revealed the presence of absorption bands the ranges of which and the corresponding functional groups are given in Table 4 and sample spectra in Figure 2 (Gonet, 1989; Debska, 2004; Enev et al., 2014; Zhang et al., 2017; Hayes \& Swift, 2018).

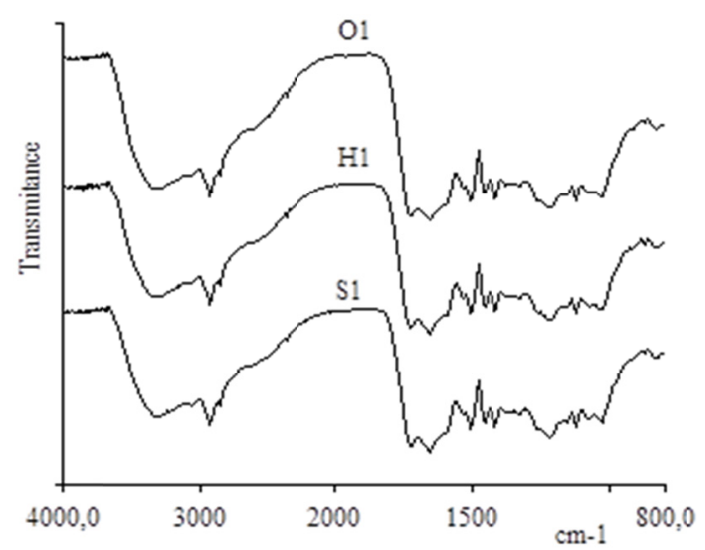

Figure 2. FT-IR spectra of selected humic acids

The intensity of absorption bands isolated from the soil sampled from $0-15 \mathrm{~cm}$ layer, irrespective of the tillage method, was similar. The differences were observed for the humic acids of deeper layers. The HAs of $15-30 \mathrm{~cm}$ layer of the soil with ploughless tillage and strip-till demonstrated the highest intensity of band $1730-1710 \mathrm{~cm}^{-1}$ and a lower-1520-1500, 1420-1400 and $1130 \mathrm{~cm}^{-1}$ as compared with HAs of soil under plough tillage. In 30-50 $\mathrm{cm}$ layer the highest intensity of band $1730-1710 \mathrm{~cm}^{-1}$ and lower $1520-1500,1420-1400$ and $1130 \mathrm{~cm}^{-1}$ were recorded for HAs of soil with ploughless tillage. In FT-IR spectra for HAs of the soil with strip-till there was found a higher intensity of bands $1520-1500$ and $1420-1400 \mathrm{~cm}^{-1}$ as well as lower $1460-1440 \mathrm{~cm}^{-1}$ as compared with HAs of the soil under plough tillage. Further it must be stressed that for the humic acids of the soil under plough tillage, significant changes in the pattern of FT-IR spectra were noted between the HAs of 0-30 cm layers and HAs of $30-50 \mathrm{~cm}^{-1}$ layer. The HAs of $30-50 \mathrm{~cm}^{-1}$ layer showed a higher absorbance for band $1730-1710 \mathrm{~cm}^{-1}$ and lower-for bands in the range of $2960-2920$ and $2850 \mathrm{~cm}^{-1}$ as well as bands $1520-1500$ and $1420-1400 \mathrm{~cm}^{-1}$ as compared with HAs of layers $0-30 \mathrm{~cm}$. For the HAs under strip-till significant changes in the pattern of spectra were noted between the humic acids of 0-15 cm layer and HAs of $15-50 \mathrm{~cm}$ layers. The HAs of $15-50 \mathrm{~cm}$ layer revealed a higher absorbance of band 1730-1710 $\mathrm{cm}^{-1}$ and lower-for bands in the range 1520-1500, 1420-1400 and $1130 \mathrm{~cm}^{-1}$. In the spectra of HAs of the soil under ploughless tillage there was noted a difference in the intensity of the bands for each depth. The intensity of the band in the range $1730-1710 \mathrm{~cm}^{-1}$ was increasing, and bands $2960-2920$ and $2850 \mathrm{~cm}^{-1}$ as well as $1520-1500$ and $1420-1400 \mathrm{~cm}^{-1}$ and $1130 \mathrm{~cm}^{-1}$ — was decreasing with depth.

Table 4. List of peaks (bands) present in FT-IR spectra

\begin{tabular}{ll}
\hline Wavenumber $\left(\mathrm{cm}^{-1}\right)$ & Assignment \\
\hline $3400-3100$ & O-H stretching of alcohols, phenols and acids, N-H stretching \\
$3100-3000$ & C-H groups of aromatic and alicyclic compounds \\
$2960-2920 ; 2850$ & asymmetric and symmetric $\mathrm{C}-\mathrm{H}$ stretching of $\mathrm{CH}_{3}$ and $\mathrm{CH}_{2}$ group \\
$1730-1710$ & $\mathrm{C}=\mathrm{O}$ stretching of carboxyl, aldehyde, ketone group \\
$1660-1620$ & $\mathrm{C}=\mathrm{O}$ of stretching of amide groups; $\mathrm{N}-\mathrm{H}$ deformation; \\
$1610-1600$ & $\mathrm{C}-\mathrm{C}$ stretching of aromatic rings \\
$1550-1530$ & N-H deformation, $\mathrm{C}=\mathrm{N}$ stretching (amide II bands) \\
$1520-1500$ & $\mathrm{C}-\mathrm{C}$ stretching of aromatic rings \\
$1460-1440$ & $\mathrm{C}-\mathrm{H}$ asymmetric of $\mathrm{CH}_{3}$ and $\mathrm{CH}_{2}$ \\
$1420-1400$ & $\mathrm{C}-\mathrm{O}$ stretching and $\mathrm{OH}$ deformation of phenols \\
$1380-1320$ & $\mathrm{C}-\mathrm{N}$ aromatic amine, $\mathrm{COO}-, \mathrm{C}-\mathrm{H}$ stretching \\
$1280-1200$ & $\mathrm{C}-\mathrm{O}$ stretching of aryl ethers, esters and phenols \\
$1160-1030$ & C-O stretching alcohols, ethers and polysaccharides \\
\hline
\end{tabular}


Changes in the intensity of absorption bands show that the molecules of HAs from the deepest layer $(30-50 \mathrm{~cm})$ are identified with a higher degree of oxidation (a higher intensity of the band pointing to the presence of carbonyl groups), a lower share of aliphatic structures (bands 2960-2920 and $2850 \mathrm{~cm}^{-1}$ ) and simple aromatic structures (1520-1500 and 1420-1400 $\mathrm{cm}^{-1}$ ) as compared with HAs of topsoil. As reported by e.g., Carvalho et al. (2009), Gonet and Debska (1998), it can signify a lower "degree of maturity" of the HAs isolated from topsoil, due to the inflow of fresh organic matter (post-harvest residue). As seen from the results, the tillage method affects the structure of humic acids distributed in the soil profile. For plough tillage and strip-till the changes in the structure of humic acids occur between 0-30 layer and 30-50 cm layer and, as for ploughless tillage, the differences in the pattern of spectra between the HAs of each layer were noted $(0-15 ; 15-30$ and $30-50 \mathrm{~cm})$. The dependencies are confirmed by the results of the parameters discussed earlier. With the results one can conclude that the humic acids of the soil under plough tillage show a lower degree of humification as compared with HAs of ploughless tillage, whereas the parameters recorded for the HAs of the soil with strip-till point to the similarity to HAs of soil with plough tillage and ploughless tillage. As provided in the introduction, abandoning plough tillage and introducing simplified tillage, including strip-till, results in the accumulation of organic carbon (Islam et al., 2015; Strickland et al., 2015; Al-Kaisi et al., 2014; Fernandez et al., 2015). Applying ploughless tillage and, to some extent, strip-till decreases the intensity of mineralization not only of fresh organic matter but also humus substances, as well as slows down the processes of humification of fresh organic matter. As a result, HAs of soil with ploughless tillage demonstrated the highest degree of maturity, and thus stability, which is of great importance for carbon sequestration process.

To obtain complete information on the differences (similarities) of humic acids depending on the tillage method, the cluster analysis was applied. The cluster analysis results the HAs isolated from the $0-15 \mathrm{~cm}$ and $15-30 \mathrm{~cm}$ layers are given in Figure 3 and involved the parameters discussed (elemental composition, UV-VIS parameters and hydrophilic, hydrophobic properties). The dendrograms obtained show clearly that the properties of humic acids are determined by the tillage method. Humic acids under ploughless tillage (H1, H2) and strip-till (S1, S2) constituted one group; the HAs of the plough tillage system $(\mathrm{O} 1, \mathrm{O} 2)$ were found outside it. Those dependencies referred to both the humic acids isolated from the $0-15$ and $15-30 \mathrm{~cm}$ layer.
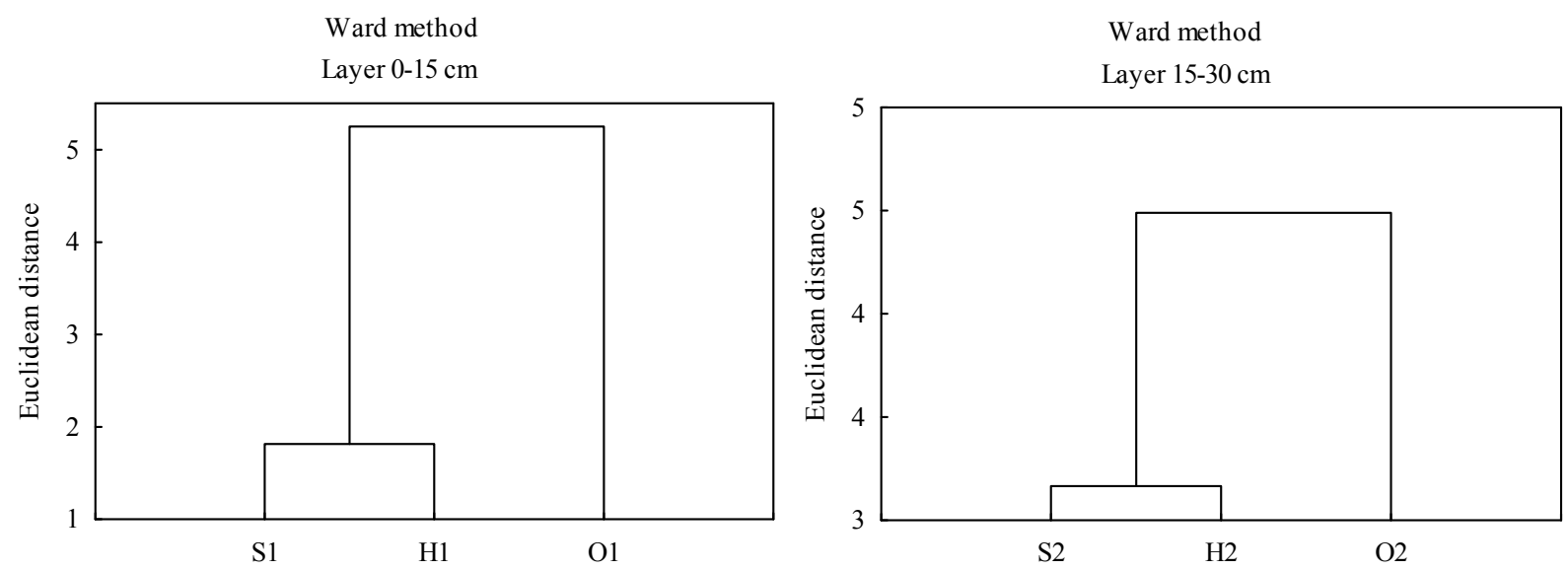

Figure 3. Cluster analysis of humic acids determined based on the following parameters: elemental composition, $\mathrm{A}_{2 / 4}, \mathrm{~A}_{2 / 6}, \mathrm{~A}_{4 / 6}, \Delta \log \mathrm{K}, \mathrm{HIL} / \Sigma \mathrm{HOB}$

Fernandez et al. (2015) show that strip-till is a method of tillage and plant cultivation facilitating the accomplishment of the basic objectives of contemporary agriculture. Similarly as other zone tillage methods (Zibilske \& Bradford, 2007; Zhu, Hu, Yang, Zhan, \& Zhang, 2014; Williams et al., 2016), it creates favourable conditions for plant growth and yielding and, at the same time, enhances the soil properties, including organic carbon management.

The quality parameters for HAs of soil with strip-till point to an increase in their degree of maturity (stability) as compared with HAs of the soil under plough tillage and their higher similarity to HAs of soil under ploughless tillage (Figure 3). Thus one can conclude the strip-till that tillage method combines two primary objectives; ensuring conditions favourable to plant growth and development and the effort to maintain the possibly highest humus stability. 


\section{Conclusions}

The results have demonstrated that the tillage system determines the properties of humic acids.

The HAs isolated from the samples of the soil with ploughless tillage, as compared with the HAs of the soil under plough tillage showed a higher content of carbon and a lower content of hydrogen and, as a result, a lower value of $\mathrm{H} / \mathrm{C}$ and higher values of $\mathrm{O} / \mathrm{H}$, the degree of internal oxidation and a higher intensity of the band $1730-1710 \mathrm{~cm}^{-1}$ related to the presence of carbonyl groups; a higher share of hydrophobic fractions and a lower share of hydrophilic fractions and, as a result, a lower value of the ratio HIL/ $/ \mathrm{HOB}$.

The HAs of the soil with the strip-till applied, as compared with the HAs of the soil under plough tillage, demonstrated a higher value of internal oxidation, lower values of the ratios: $\mathrm{A}_{2 / 6}, \mathrm{~A}_{4 / 6}$ and coefficient $\Delta \operatorname{logK}$; a lower value of HIL/ $\mathrm{EHOB}$; a higher share of carbonyl groups and a lower-1520-1500, 1420-1400 and $1130 \mathrm{~cm}^{-1}$ bands (correspondingly as the ploughless method).

The dependencies and the application of the cluster analysis have shown that the degree of maturity (stability) of HAs can be ordered as follows: HAs with plough tillage $<$ HAs with strip-till $<$ HAs with ploughless tillage.

\section{References}

Al-Kaisi, M. M., Douelle, A., \& Kwaw-Mensah, D. (2014). Soil microaggregate and macroaggregate decay over time and soil carbon change as influenced by different tillage systems. Journal of Soil and Water Conservation, 69(6), 574-580. https://doi.org/10.2489/jswc.69.6.574

Busari, A. M., Kukal, S. S., Kaur, A., Bhatt, R., \& Dulazi, A. A. (2015). Conservation tillage impacts on soil, crop and the environment. International Soil and Water Conservation Research, 3, 119-129.

Carvalho, A. M., Bustamante, M. M. C., Alcantara, F. A., Resck, I. S., \& Lemos, S. S. (2009). Characterization by solid-state CPMAS ${ }^{13} \mathrm{C}$ NMR spectroscopy of decomposing plant residues in conventional and no-tillage systems in Central Brazil. Soil and Tillage Research, 102, 144-150. https://doi.org/10.1016/j.still.2008. 08.006

Cocozza, C., \& Miano, T. (2002). Structural resolution of metal-humic acids interactions through deconvolution FT-IR spectroscopy. Proceedings of the 11th IHSS Meeting (pp. 264-266). Boston, USA.

Debska, B., Maciejewska, A., \& Kwiatkowska, J. (2002). The effect fertilization with brown coal on Haplic Luvisol humic acids. Rostlinna Vyroba, 48(1), 33-39.

Debska, B. (2004). Properties of humic substances of soil fertilized with slurry (PhD Diss. 110, UTA, Bydgoszcz).

Debska, B., Banach-Szott, M., Dziamski, A., \& Gonet, S. S. (2010). Chromatographic characteristics (HPLC, HPSEC) of humic acids of soil fertilised with various organic fertilisers. Chemistry and Ecology, 26(S2), 49-57.

Debska, B., Drag, M., \& Tobiasova, E. (2012). Effect of post-harvest residue of maize, rapeseed, and sunflower on humic acids properties in various soils. Polish Journal of Environmental Studies, 21(3), 603-613.

Dou, S., Zhang, J. J., \& Li, K. (2008). Effect of organic matter applications ${ }^{13} \mathrm{C}-\mathrm{NMR}$ spectra of humic acids of soil. European Journal of Soil Science, 59, 532-539.

Enev, V., Pospisilova, L., Klucakova, M., Liptaj, T., \& Doskocil, L. (2014). Spectral characterization of selected humic substances. Soil and Water Research, 9(1), 9-17 https://doi.org/10.17221/39/2013-SWR

Fernandez, F. G., Sorensenb, B. A., \& Villamil, M. B. (2015). A comparison of soil properties after five years of no-till and strip-till. Agronomy Journal, 107(4), 1339-1346.

Ferreira, F. P., Vidal-Torrado, P., Otero, X. L., Buurman, P., Martin-Neto, L., Boluda, R., \& Macias, F. (2013). Chemical and spectroscopic characteristics of humic acids in marshes from the Iberian Peninsula. Journal of Soils and Sediment, 13, 253-264. https://doi.org/10.1007/s11368-012-0607-9

Friedrich, T., Derpsch, R., \& Kassam, A. H. (2012). Global overview of the spread of conservation agriculture. Journal of Agricultural Science and Technology, 6, 1-7.

Gomes de Melo, B. A., Motta, F. L., \& Santana, M. H. A. (2016). Humic acids: Structural properties and multiple functionalities for novel technological developments. Materials Science and Engineering C, 62, 967-974.

Gomez, K. A., \& Gomez, A. A. (1983). Statistical procedures for agricultural research. New York: John Wiley and Sons.

Gonet, S. S. (1989). Properties of humic acids of soils of varied fertilisation (PhD Diss. 33, UTA, Bydgoszcz). 
Gonet, S. S., \& Debska, B. (1998). Properties of humic acids developed during humification process of post-harvest plant residues. Environment International, 24(5/6), 603-608.

Hayes, M. H. B., \& Swift, R. S. (2018). An appreciation of the contribution of Frank Stevenson to the advancement of studies of soil organic matter and humic substances. Journal of Soils and Sediment, 18(4), 1212-1231. https://doi.org/10.1007/s11368-016-1636-6

Islam, A. K. M. S., Saleque, M. A., Hossain, M. M., \& Islam, A. K. M. A. (2015). Effect of conservation tillage on soil chemical properties in rice-maize cropping system. The Agriculturists, 13(2), 62-73.

Kumada, K. (1985). Elementary composition and absorption spectra of humic and fulvic acids. Soil Science and Plant Nutrition, 31(3), 437-448.

Kumada, K. (1987). Chemistry of soil organic matter. Tokyo: Japan Sc. Soc. Press, Amsterdam: Elsevier.

Kwiatkowska-Malina, J. (2015). The comparison of the structure of humic acids from soil amended with different sources of organic matter. Polish Journal of Soil Science, 48(1), 57-64. https://doi.org/10.17951/pjss/ 2015.48.1.57

Morris, N. L., Miller, P. C. H., Orson, J. H., \& Froud-Williams, R. J. (2010). The adoption of noninversion tillage systems in the United Kingdom and the agronomic impact on soil, crops and the environment-A review. Soil and Tillage Research, 108, 1-15.

Powlson, D. S., Bhogal, A., Chambers, B. J., Coleman, K., Macdonald, A. J., Goulding, K. W. T., \& Whitmore, A. P. (2012). The potential to increase soil carbon stocks through reduced tillage or organic material additions in England and Wales: A case study. Ecosystems and Environment, 146, 23-33.

Rodriguez, F. J., Schlenger, P., \& Garcia-Valverde, P. (2016). Monitoring changes in the structure and properties of humic substances following ozonation using UV-Vis, FTIR and ${ }^{1} \mathrm{H}$ NMR techniques. Science of the Total Environment, 541, 623-637. https://doi.org/10.1016/j.scitotenv.2015.09.127

Si, P., Liu, E., He, W., Sun, Z., Dong, W., Yan, Ch., \& Zhang, Y. (2018). Effect of no-tillage with straw mulch and conventional tillage on soil organic carbon pools in Northern China. Archives of Agronomy and Soil Science, 64(3), 398-408. https://doi.org/10.1080/03650340.2017.1359410

Strickland, T. C., Scully, B. T., Hubbard, R. K., Sullivan, D. G., Abdo, Z., Savabi, M. R., ... Hawkins, G. L. (2015). Effect of conservation practices on soil carbon and nitrogen accretion and crop yield in a corn production system in the southeastern coastal plain, United States. Journal of Soil and Water Conservation, 70(3), 170-181. https://doi.org/10.2489/jswc.70.3.170

Tan, H. K. (2012). Humic matter in soil and the environment (2nd ed.). Boca Raton: CRC Press.

Tinoco, P., Almendros, G., Francisco, J., Gonzalez-Vila, F. J., Sanz, J., \& Gonzalez-Perez, J. A. (2015). Revisiting molecular characteristics responsive for the aromaticity of soil humic acids. Journal of Soils and Sediment, 15, 781-791. https://doi.org/10.1007/s11368-014-1033-y

Trubetskaya, O., Trubetskoj, O., \& Richard, C. (2014). Hydrophobicity of electrophoretic fractions of different soil humic acids. Journal of Soils and Sediment, 14, 292-297. https://doi.org/0.1007/s11368-013-0667-5

Williams, A., Kane, D. A., Ewing, P. M., Atwood, L. W., Jilling, A., Li, M., .. Jordan, N. R. (2016). Soil Functional Zone Management: A Vehicle for Enhancing Production and Soil Ecosystem Services in Row-Crop Agroecosystems. Frontiers in Plant Science, 7, 65. https://doi.org/10.3389/fpls.2016.00065

World Reference Base for Soil Resources. (2014). Food and Agriculture Organization of the United Nations World Soil Resources Reports 103 (p. 132). Rome: FAO.

Zhang, J., Wang, J., An, T., Wei, D., Chi, F., \& Zhou, B. (2017). Effects of long-term fertilization on soil humic acid composition and structure in Black Soil. Plos One, 12(11), 1-14. https://doi.org/10.1371/journal.pone. 0186918

Zhu, L., Hu, N., Yang, M., Zhan, X., \& Zhang, Z. (2014). Effects of different tillage and straw return on soil organic carbon in a rice-wheat rotation system. Plos One, 9(2), e88900, 1-7.

Zibilske, L. M., \& Bradford, J. M. (2007). Soil aggregation, aggregate carbon and nitrogen, and moisture retention induced by conservation tillage. Soil Science Society of America Journal, 71, 793-802. https://doi.org/ 10.2136/sssaj2006.0217 


\section{Copyrights}

Copyright for this article is retained by the author(s), with first publication rights granted to the journal.

This is an open-access article distributed under the terms and conditions of the Creative Commons Attribution license (http://creativecommons.org/licenses/by/4.0/). 